\title{
Oxidants, Antioxidants, and Delayed Language Correlations in Children with Autism
}

\author{
Azab SN ${ }^{1 *}$, Saber $\mathrm{AS}^{2}$ and Mostafa $\mathrm{HA}^{1}$ \\ ${ }^{1}$ Department of Otorhinolaryngology, Faculty of \\ Medicine, Beni- Suef University, Egypt \\ ${ }^{2}$ Department of Otorhinolaryngology, Faculty of \\ Medicine, Ain Shams University, Egypt \\ *Corresponding author: Safinaz Nagib Azab, \\ Department of Otorhinolaryngology, Faculty of Medicine \\ Beni- Suef University, Egypt
}

Received: October 21, 2017; Accepted: November 15, 2017; Published: November 22, 2017

\begin{abstract}
Autism is complexes behaviorally known as neurodevelopmental disorder characterized by significant deterioration in social interaction, mental abilities language development and other communicative abilities. It is deemed a multicauses disorder that is affected by genetic, immunological and environmental factors and inclusive oxidative stress. Aim of such study was to estimate level of antioxidant enzyme coenzyme Q10 and level of malondialdehyde (MDA) in children with autism and correlate these results with their language and behavior pattern. The study included 30 Egyptian children with autism and 30 normal children as control group. Their ages ranged between 3 to 6 years. Diagnosis was done using DSM-V and ADI-R. Cases were classified into high and low functioning autism using CARS. We compared plasma levels of coenzyme Q10 and MDA in children with autism and controls. Our results showed significant increased MDA and decreased coenzyme Q10 in autistic children compared to controls. On the other hand, Increased MDA and decreased coenzyme Q10 were not related to severity of autistic features and language abilities among autistic children group. Regarding language abilities of autistic children, there was positive correlation between IQ and total language age and negative correlation between CARS and total language age.
\end{abstract}

\section{Introduction}

Autism and its affined spectrum of disorders (ASD) are neurodevelopmental disorders distinguished by fundamental feebleness in social interaction, difficulty with communication, and restrictive and repetitive conducts [1]. Mitochondrial disorders are one of the most joint metabolic diseases in children. Mitochondrial diseases occur in a subset of autism cases and are usually caused by genetic abnormality or mitochondrial respiratory pathway anomalisms. They have also been correlated with developmental retraction and retardation in ASD comprehensive missing language expertise, hyperactivity, unusual social interaction, limited interests, stereotypical demeanors, seizures, and self-detrimental behaviors [2]. The free radicals are produced endogenously through oxidative metabolism and energy fabrication by mitochondria where the electron transport chain in mitochondria is a first provenance of reactive oxygen species (ROS) production [3]. ROS have the ability to rush pivotal components of the cell, as polyunsaturated fatty acids, proteins, and nucleic acid. These reflections can modify fundamental membrane properties such as enzyme activities, fluidity, ion transport, protein synthesis and protein cross-linking finally resulting in cell death [4]. Neuronal cells are extremely susceptible to oxidative stress due to the high rate of oxygen distribution and consumption in the brain [5]. Mitochondrial Coenzyme Q functions comprise arranger of electron transport in the respiratory chain, extraditing electrons from complex I, complex II, and passing them to complex III, and relocate protons from fatty acids to matrix. As an alternative Coenzyme Q function is possible in organization of permeability transition pore opening and nutrition absorption through the Voltage Dependent Anion Channel of outer mitochondrial membrane. Ubiquinol supportive therapy may improve brain mitochondrial function and
ATP production and affect brain oxidative stress [6].

\section{Aim of the Work}

The aim of the study was to estimate level of antioxidant enzyme coenzyme Q10 and malondialdehyde in children with autism and correlate these results with their behavior and language.

\section{Materials and Methods}

\section{Subjects}

The present study included 60 children aged 3-6 years, 30 children of them were diagnosed as autism (patients Group) and a comparable 30 normally developed children served as (control Group), both groups were matching regarding age and gender. Caregivers consent was obtained for all the studied cases and controls. The cases were recruited from Beni-Suef University Hospital and subjected to detailed history taking including three generation pedigrees construction, detailed peri- and postnatal history, similarly affected cases and other family findings. Thorough clinical examination with special emphasis on vocal tract examination and psychometric evaluation using Stanford Binet intelligence scale fifth edition [7] were done. Language assessment protocol [8] was applied in Phoniatric Unit in addition to EEG were applied for all autistic cases. Diagnosis of the cases were confirmed using Autism Diagnostic Interview-Revised (ADI-R) [9] and Clinical interview based on Diagnostic and Statistical Manual of Mental Disorders, 4the edition (DSM-IV) [10] in the Autistic Children Clinic, National Research Center, Cairo, Egypt. Severity was assessed using the childhood autism rating scale CARS [11].

\section{Blood sampling}

Venous blood sample was collected from all patients and controls into vacationer tubes containing EDTA. We measured plasma MDA
Phys Med Rehabil Int - Volume 4 Issue 6 - 2017

ISSN : 2471-0377 | www.austinpublishing group.com

Azab et al. (@) All rights are reserved
Citation: Azab SN, Saber AS and Mostafa HA. Oxidants, Antioxidants, and Delayed Language Correlations in Children with Autism. Phys Med Rehabil Int. 2017; 4(6): 1134. 
Table 1: Percentage of family history.

\begin{tabular}{|c|c|c|c|}
\hline Items & $\begin{array}{c}\text { Patient group } \\
\text { no. }=30\end{array}$ & Frequency & $\%$ \\
\hline \multirow{2}{*}{ E.E.G } & Negative & 27 & 90 \\
\hline & Positive & 3 & 10 \\
\hline \multirow{2}{*}{ Family history (similar condition) } & Negative & 28 & 93.3 \\
\hline & Positive & 2 & 6.7 \\
\hline \multirow{2}{*}{$\begin{array}{l}\text { Family history (other neuropsychiatric } \\
\text { cases) }\end{array}$} & Negative & 27 & 90 \\
\hline & Positive & 3 & 10 \\
\hline
\end{tabular}

Table 2: Differentiation among patient and control groups.

\begin{tabular}{|c|c|c|c|c|}
\hline Items & Patient Mean \pm SD & Control Mean \pm SD & P value & Sig. \\
\hline IQ & $75.7 \pm 6.0$ & $108.5 \pm 5.1$ & 0.001 & HS \\
\hline CARS & $33.5 \pm 3.8$ & $17.1 \pm 1.6$ & 0.001 & HS \\
\hline LA (YEAR) & $1.6 \pm 0.3$ & $5.2 \pm 1.4$ & 0.001 & HS \\
\hline
\end{tabular}

Table 3: Differentiation among patient and control groups concerning biochemical markers (lipid peroxide and coenzyme Q10).

\begin{tabular}{|c|c|c|c|c|}
\hline Items & Patient Mean \pm SD & Control Mean \pm SD & P value & Sig \\
\hline $\begin{array}{c}\text { Chemistry } \\
\text { Lipid peroxide }(\mathrm{nmol} / \\
\mathrm{ml})\end{array}$ & $1.2 \pm 0.4$ & $0.6 \pm 0.2$ & 0.001 & HS \\
\hline Coenzyme Q10 $(\mu \mathrm{g} / \mathrm{ml})$ & $0.5 \pm 0.3$ & $1.0 \pm 0.5$ & 0.001 & HS \\
\hline
\end{tabular}

as an indicator of lipid peroxidation status in all autistic children and control subjects according to the method described by Chauhan et al. 2004 [12] and plasma concentrations of both the total and the reduced CoQ10 (ubiquinol) according to the method described by Jiang et al., 2004 [13] using Elisa system.

\section{Statistical analysis}

Data were expressed as mean \pm SD. Statistical significance was determined using an Cross tabulation test, student t- test and fisher's exact test. A probability value of $P$ less than 0.05 was considered statistically significant. Bivariate comparisons were examined using Pearson's and Spearman's correlation coefficients for parametric and nonparametric variables. P values less than 0.05 was considered statistically significant.

\section{Results}

The results showed no significant difference in mean of age of cases compared to control groups ( $\mathrm{P}$ value is $>0.05$ ). Parental consanguinity variation between patient and control groups was measured by Cross tabulation test with no significant difference and the parental age of patient group was older than parental age of control group with highly significant statistical difference (P value $<0.01$ ). The percentage of electroencephalogram (EEG) changes among patient group $(10 \%=3$ out of 30 children in the patient group have EEG findings) (Table 1). Table 1 showed the percentage of family history with similar condition or other neuropsychiatric cases among patient group. Table 2 showed that the mean of intelligence quotient in patient group was significantly decreased compared to control group. The mean score of total language age among patient group is lower than control group with high significant difference while mean of CARS is higher in patient group than in control group. The average score of intelligence quotient and of total language in patient group was lower than control group. The mean score of CARS is greater in patient groupthan control group (Table 2).

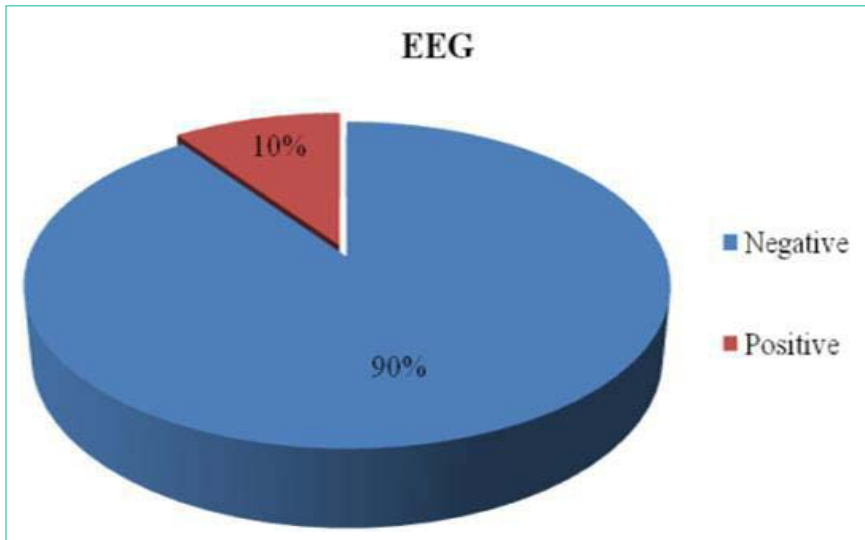

Figure 1: Percentage of EEG among autistic group.
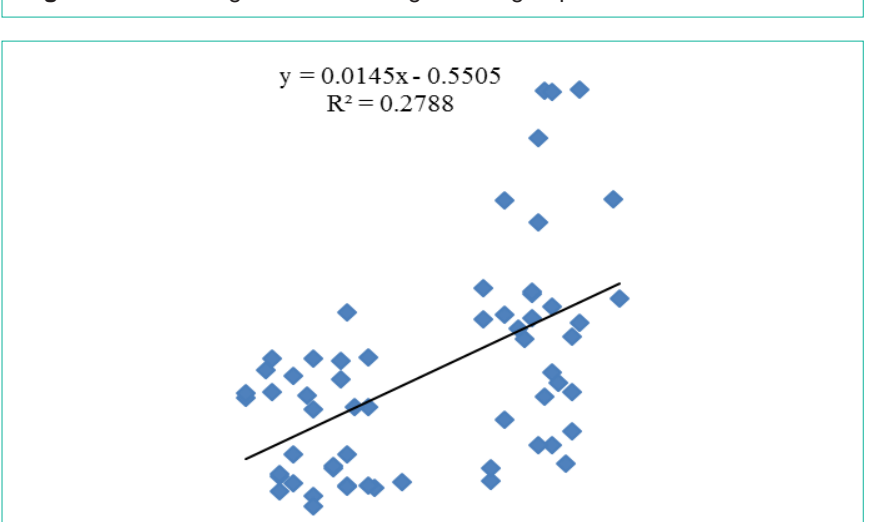

Figure 2: Correlation between Coenzyme Q10 level and IQ.

"HS" highly significant difference $(P<0.001)$.

The results showed that mean concentration of lipid peroxide was significantly high and coenzyme Q10 was significantly low in patient group compared to control children, (Figure 1) (Table 3).

"HS" highly significant difference $(P<0.001)$.

Person's correlation coefficients were calculated between plasma Coenzyme Q10 level and IQ. The correlation between Coenzyme Q10 level and IQ showed positive correlation (Figure 2).

\section{Discussion}

This study addressed an important area in autism research evaluation levels of the antioxidant coenzyme Q10 and lipid peroxidation marker MDA in autistic children and correlates these results with their behavior and language skills in order to highlight the suitable way for intervention. Maternal age may be correlated with autism due to increased risk of chromosomal anomalies in ova at increased age. Marissa et al., 2009 [14] reported that the parental characteristics correlated with an intensified risk of autism and autism spectrum disorders include advanced maternal age. This agrees with results in the current study which showed increased maternal age of children with autism more than that maternal age of normal children. Regarding paternal age of autistic children it was older than paternal age of normal children, this result agrees with Reichenberg et al., 2006 [15] who observed that there was a combination among advancing paternal age and risk of ASD. They suggested that accumulate with progressing age in spermatagonia or confusing by sociocultural 
environmental factors. The electroencephalogram (EEG) is a premiere tool to appreciate neural impairment related to autism. In the current study, $10 \%$ of autistic children had epileptic focus in EEG, with and without history of seizures. Epileptic form abnormalities on EEG are common in children with ASDs, with reported rats ranging from $10 \%$ to $72 \%$. Some studies have suggested that epileptic form anomalies on EEG and/or epilepsy are more common in the subgroup of children with ASDs who have a history of retraction, whereas other studies have not demonstrated this association [16]. Neuropsychiatric disorders are caused by combination genetic variants and environmental factors. The exact format of psychopathology expressed thus emerges from a complex combination of changes in cognitive, perceptual and influential capacity [17]. This agreed with results in the current study where $10 \%$ of autistic children had family history of other neuropsychiatric disorders (Mental retardation and brain damage motor handicap BDMH). Baron-Cohen et al., 2006 [18] reported that autistic children have spectrum of intelligence quotient (IQ) ranged from 0 to 60 . On the other hand, Farida et al., 2011 [19] reported that autistic children in Egypt had variable IQ abilities ranging between average IQ, below average IQ, mild mental retardation (MR), moderate MR and sever MR which agrees with the current study; autistic children had significant decrease in IQ less than control children which ranges between below average, borderline IQ and mild mental retardation. According to statistical manual-IV (DSM-IV) children of ASDs suffer from qualitative impairment in social interaction. Volkmar et al., 2009 [20] concluded that social impairments and behavioral problems were recognizable in ASDs diagnosed children as poor eye contact, inability to utilize nonverbal gestures, and inability to play in the same route as typically developing children. Another study done by Zhongguo, 2006 [21] reported that autistic children presented a sequence of abnormal behaviors, comprising absence of social smile, no response to own name, no eye contact and delay in language. These studies agreed with features of autistic children under the current study which measured by DSM-IV and scored by childhood autism rating scale (CARS) and autism diagnostic interview revised test (ADIR). The social deterioration in individuals with ASD is assorted and involves linguistic conventions, speech and interpersonal interaction [22]. Jon et al., 2008 [23] reported that about a third to a half of individuals with autism do not develop enough normal language to meet their daily communication needs. Specifically on language, delays in the acquisition and development of this ability are common in individuals with ASD and the linguistic impairments in these individuals may be present in morphology, phonology, syntax, semantics and pragmatics. In the present work, highly significant decrease of language abilities of autistic children was present compared to normal group. Increased oxidative stress in autism is one of environmental factors that affect genetically predisposed autistic children. Rossignol and Frye. 2012 [24] have reported that levels of malonyldialdehyde are increased in the plasma of children with autism. Autistic children under the current study suffered from oxidative stress in the form of highly significant increase in MDA and highly significant decrease in the level of antioxidant coenzyme Q10 compared to controls. This could be explained by deficits in redox system. A defect in redox metabolism was referred to by Gvozdjáková et al., 2014 [6] who attributed these defects to alterations in levels of antioxidants which are significantly lower in autistic children than controls, while MDA is significantly high indicating increased susceptibility to oxidative stress between autistic children. Language age and other autistic features measured by CARS and ADI-R showed no significant correlation with oxidative stress biomarkers, lipid peroxidation and coenzyme Q10.

\section{Conclusion}

Autistic children are more susceptible to oxidative stress. Soon appreciation of antioxidant status would have best prediction as it may decrease the oxidative stress before invigorate more irreversible brain damage. Plasma concentration of $\mathrm{CoQ} 10$ and lipid peroxidation could be used as relevant biomarkers of ubiquinol supportive therapy.

\section{References}

1. Rossignol $A A$ and Bradstreet $\mathrm{JJ}$. Evidence of mitochondrial dysfunction in autism and implications for treatment. American journal of biochemistry and biotechnology. 2008; 4: 208-217.

2. Poling JS, RE Frye, Shoffner AW. Zimmerman. Developmental regression and mitochondrial dysfunction in a child with autism. J. Child Neurol. 2006; 21: $170-172$

3. Frustaci A, Neri M, Cesario A, Adams JBd, Domenici $E$, Bernardina BD, et al. Oxidative stress- related biomarkers in autism: Systematic view and metaanalyses. Free Radical Biology and Medicine. 2012; 52: 2128-2141.

4. Sharma P, Jha AB, Dubey RS, and Pessarakli M. Reactive Oxygen Species, Oxidative Damage, and Ant oxidative Defense Mechanism in Plants under Stressful Conditions. Journal of Botany. 2012; 2012.

5. Uttara B, Singh AV, Zamboni $P$ and Mahajan RT. Oxidative Stress and Neurodegenerative Diseases: A Review of Upstream and Downstream Antioxidant Therapeutic Options. Current Neuropharmacology. 2009; 7: 6574.

6. Gvozdjáková A, Kucharská J, Ostatníková D, Babinská K, Nakládal D, and Fred L. et al. Ubiquinol Improves Symptoms in Children with Autism. Oxidative Medicine and Cellular Longevity. 2014; 2014.

7. Roid, GH: Stanford-Binet Intelligence Scales, Fifth Edition: Technical Manual. Itasca, IL: Riverside Publishing. 2003.

8. Kotby MN, Khairy A, Baraka M, Rifaie N, and El-Shobary A. Language Testing of Arabic Speaking Children. In M. N. Kotby (Ed.), Proceedings of the XXIII World Congress of the IALP 1995; (pp. 263:266). Cairo, Egypt: The Organizing Committee.

9. Lord C, Rutter M, and LeCouteur A. Autism Diagnostic Interview Revised: A revised version of the autism diagnostic interview for caregivers of individuals with possible pervasive developmental disorders. Journal of Autism and Developmental Disorders. 1994; 24: 659-685.

10. American Psychiatric Association. Diagnostic and statistical manual of mental disorders IV Washington, DC: Author. 1994.

11. Schopler E, Reichler R, Rochen Renner B. The childhood autism rating scale. Western Psychological Services. 1988.

12. Chauhan V, Chauhan A, Cohen IL, Brown WTand Sheikh A. Alteration in amino-glycerophospholipids levels in the plasma of children with autism: a potential biochemical diagnostic marker, Life Sci. 2004; 74: 1635-1643.

13. Jiang $P$, Wu M, Zeheng $Y$, Wang C, Li Y, Xin J, Xu G. Analysis of coenzyme Q10 in human plasma by column-switching liquid chromatography. Journal of Chromatography B. 2004; 805: 297-301.

14. Marissa DK, Christine F, Diana DBA and Peter SB. Estimated autism risk and older reproductive age. Am J Public Health. 2009; 99: 1673-1679?

15. Chez MG, Chang M, Krasne V, Coughlan C, Kominsky M. and Schwartz A. Frequency of epileptiform EEG abnormalities in a sequential screening of autistic patients with no known clinical epilepsy from 1996 to 2005. Epilepsy Behav. 2006; 8: 267-271.

16. Campbell BC and Wang SS-H. Familial Linkage between Neuropsychiatric Disorders and Intellectual Interests. Familial Neuropathology and Intellectual Interests. 2012. PLoS ONE 7(1) 
17. Baron-Cohen S. The hyper-systemizing, assortative mating theory of autism: Prog Neuropsychopharmacol Biol Psychiatry. 2006; 30: 865-872.

18. Farida El-Baz, Nanees Ahmed Ismael, Sahar M. and Nour El-Din. Risk factors for autism: An Egyptian. The Egyptian Journal of Medical Human Genetics. 2011; 12: 31-38.

19. Volkmar FR, State $M$ and Klin A. Autism and autism spectrum disorders: diagnostic issues for the coming decade. J Child Psychol Psychiatry. 2009; 50: 108-115.

20. Zhongguo Xi CY, Ma HW, Hua TY, Zhao YJ. Behavioral patterns of autistic children during infancy. Chinese J ContempPediatr. 2006; 8: 470-472.
21. Erin D Bigler, Sherstin Mortensen, E Shannon Neeley, Sally Ozonoff, Lori Krasny, Michael Johnson, et al. Superior Temporal Gyrus, Language Function, and Autism. Developmental Neuropsychology. 2007; 31: 217-238.

22. Jon B, Courtenay N, Shiri E and Kate N. Do individuals with autism process words in context? Evidence from language-mediated eye-movements. 2008; 108: 896-904.

23. Rossignol DA, Frye RE. Mitochondrial dysfunction in autism spectrum disorders: a systematic review and meta-analysis. 2012; 17: 290-314.
Phys Med Rehabil Int - Volume 4 Issue 6 - 2017

ISSN : 2471-0377 | www.austinpublishinggroup.com

Azab et al. (C) All rights are reserved
Citation: Azab SN, Saber AS and Mostafa HA. Oxidants, Antioxidants, and Delayed Language Correlations in Children with Autism. Phys Med Rehabil Int. 2017; 4(6): 1134 